\title{
BMJ Open Association between mobile phone use and self-reported well-being in children: a questionnaire-based cross- sectional study in Chongqing, China
}

\author{
Feizhou Zheng, ${ }^{1}$ Peng Gao, ${ }^{1}$ Mindi He, ${ }^{1}$ Min Li, ${ }^{1}$ Jin Tan, ${ }^{2}$ Daiwei Chen, ${ }^{3}$
} Zhou Zhou, ${ }^{1}$ Zhengping Yu, ${ }^{1}$ Lei Zhang ${ }^{1}$

To cite: Zheng F, Gao P, $\mathrm{He} \mathrm{M}$, et al. Association between mobile phone use and self-reported wellbeing in children: a questionnaire-based crosssectional study in Chongqing, China. BMJ Open 2015;5: e007302. doi:10.1136/ bmjopen-2014-007302

- Prepublication history and additional material is available. To view please visit the journal (http://dx.doi.org/ 10.1136/bmjopen-2014007302).

Received 26 November 2014 Revised 13 April 2015 Accepted 15 April 2015

CrossMark

\footnotetext{
${ }^{1}$ Department of Occupational Health, Key Laboratory of Medical Protection for Electromagnetic Radiation, Ministry of Education, Third Military Medical University, Chongqing, People's Republic of China ${ }^{2}$ Shanhu Primary School, Chongqing, People's Republic of China ${ }^{3}$ Primary School Attached to the Training College, Chongqing, People's Republic of China
}

Correspondence to Dr Lei Zhang; zlep01980@163.com

\begin{abstract}
Objectives: In the past decade, the mobile phone (MP) has become extremely popular among children and the average age at which children own their first MP has decreased. The potential health effects of children's exposure to MP have been the subject of widespread public concern. The aim of our study is to investigate the associations between MP use and wellbeing in children.
\end{abstract}

Design: Cross-sectional study.

Setting: The questionnaires were completed in class with items regarding demographics, MP usage, selfreported well-being (symptoms were taken from the questionnaire of the HBSC survey) and possible confounding factors between October 2011 and May 2012 in Chongqing, China. Data were analysed using $\chi^{2}$ tests and logistic regression models.

Participants: Among the 793 children invited to participate, 781 returned the questionnaires.

Results: In total, $746(94.1 \%)$ valid questionnaires were received. Fatigue was significantly associated with the years of MP usage (OR 1.85; $95 \% \mathrm{Cl} 1.07$ to 3.22 ) and the daily duration of MP calls (OR $2.98 ; 95 \% \mathrm{Cl}$ 1.46 to 6.12$)$. Headache was significantly associated with the daily duration of MP calls (OR $2.85 ; 95 \% \mathrm{Cl}$ 1.23 to 6.57 ). However, after adjusting for confounders only, the association between fatigue and MP usage remained statistically significant. There was no significant association between MP use and other physical symptoms in children.

Conclusions: The present study indicated that there was a consistent significant association between MP use and fatigue in children. Further in-depth research is needed to explore the potential health effects of MP use in children.

\section{INTRODUCTION}

In the past decade, mobile devices are used by more people. Children own their first mobile phone (MP) at an earlier age. A study reported that the average age at which Spanish teenagers had their first MP

\section{Strengths and limitations of this study}

- We adjusted confounding factors to improve the reliability of the logistic regression results.

- There may have been some misclassification of self-reported mobile phone (MP) usage.

- We observed that fatigue was significantly associated with MP use in children.

was 13 years in $2005 .^{1}$ The average age to own first an MP was 10.4 years in Korean children and adolescents in 2011. ${ }^{2}$ Since the MP is used by children not only to keep in touch with their relatives or friends, but is also used as a source of entertainment, such as playing games and surfing the Internet, MP use has seeped into their life.

The question of whether children are more sensitive and vulnerable to electromagnetic fields produced by MPs than adults has attracted much attention due to the pervasive use of MPs by children. The Independent Expert Group on Mobile Phones (IEGMP) reported several possible reasons for the sensitivity as follows: (1) children are likely to be more vulnerable to potentially hazardous agents than adults due to their developing nervous systems, (2) owing to anatomical reasons, such as smaller heads, thinner skulls and higher tissue conductivity of their brains, children may absorb more energy from MPs than do adults, ${ }^{3}$ and (3) owing to earlier and longer exposure to MPs, children will tend to accumulate a greater risk of detrimental health effects caused by MPs. ${ }^{4}$ Considering the potential health effects of MPs on human development, research that explored the associations between MP use and well-being in children has increased gradually.

So far, there has been no explicit conclusion regarding the associations between MP 
use and well-being in children. In the studies that investigated the association between exposure to radiofrequency electromagnetic fields and symptoms in children and adolescents, participants with more exposure reported a significantly higher intensity of irritation or headache. ${ }^{5}{ }^{6}$ In addition, it was reported that children with MP exposure had higher odds of migraines and headache-related symptoms than children with no exposure. ${ }^{7}$ A population-based cross-sectional study indicated that inattention was significantly associated with MP usage in Chinese adolescents. ${ }^{8}$ Thomas $e t$ a ${ }^{9}$ found an association between exposure to measured radiofrequency fields and conduct problems in children. ${ }^{9}$ However, some controversial conclusions have been reported so far. In a double-blind experiment, shortterm wideband code division multiple access (WCDMA) radiofrequency electromagnetic fields generated no significant changes in subjective symptoms (fatigue, headache, dizziness, etc) in teenagers. ${ }^{10}$ In some neurophysiology studies, researchers were also unable to observe any exposure-related effects on the EEG or cognitive performance in participants. ${ }^{11} 12$

Owing to the uncertainty of association between MP use and well-being in children, our study aims to investigate the potential health effects of MP use on selfreported well-being in children in mainland China.

\section{METHODS}

\section{Subjects}

There were two primary schools registered in Chongqing, China that participated in this cross-sectional study. A total of 793 questionnaires were distributed to fifth grade pupils who were randomly selected using their student ID numbers between October 2011 and May 2012. After obtaining written consent from the pupils' parents or guardians, the questionnaires were distributed and collected during school hours by the research staff who had previously received epidemiological survey training. The pupils filled out the survey in the presence of their class teacher and could ask the research staff if they encountered any problems with the questions. From the $781(98.5 \%)$ questionnaires with responses, $746(94.1 \%)$ valid questionnaires were included in the final statistical analysis.

\section{Questionnaire survey}

The questionnaires were composed of four parts as follows: demographic information, information on MP usage, self-reported physical symptoms and possible confounding factors (see online supplementary 1, English version; online supplementary 2 , Chinese version).

\section{Demographic information}

The demographic information included name, sex (male/female), age, height, weight, school, grade, home address (rural/urban residence) and telephone number.

\section{Information on MP usage}

The information on MP usage included MP ownership, years of MP usage and daily duration of MP calls. To obtain information on MP ownership, pupils were asked to answer the following question: "Do you own an MP?" The years of MP usage was assessed using the following question: "How many years have you used an MP?" Last, the question "How much time do you spend on making phone calls per day (min/day)?" was used to estimate the daily duration of MP calls. For all of the above questions, MP use included use of other people's MPs.

\section{Well-being in children}

Well-being variables over the past 6 months were assessed and included headache, dizziness, fatigue, sleeping problems, feeling low and heart beating fast. The six symptoms were taken from the questionnaire of the HBSC (Health Behaviour in School-Aged Children) survey and were assessed on a 5-point Likert scale (nearly daily, several times a week, nearly every week, about once a month, seldom or never). ${ }^{13}$ A symptom was considered to be present if it was reported at least 'nearly every week'. The Cronbach's $\alpha$ coefficient of the well-being items was 0.83 .

\section{Confounding factors}

Academic stress (yes/no), daily exercise (yes/no) and having a recent cold or flu (yes/no, answer by their parents) were considered to be confounding factors as well as sex, age and home address.

\section{Statistical analysis}

$\chi^{2}$ tests were used to compare the prevalence of physical symptoms between different classifications of MP usage. Adjusted ORs and 95\% CIs were obtained using logistic regression models to assess the potential associations between the years of MP usage, the daily duration of MP calls and the prevalence of well-being symptoms in children. Adjusted ORs were also calculated after adjusting for sex, age, rural/urban residence, academic stress, daily exercise and having a recent cold or flu. Assessment of the fit between the model and the data was gauged by the goodness-of-fit test. Since the 'years of MP usage' variable was too small to split into tertiles, we considered the variable of never owning an MP as using MP 0 year, and the variable of the years of MP usage was split into using an MP for 1 year and using an MP for more than 1 year. The 'daily duration of the MP calls' variable was divided into two. In addition, a symptom was considered to be present if it was reported at least 'nearly every week'. Statistical significance was defined as $\mathrm{p}<0.05$ in this study. Categorical variables were summarised using the corresponding percentages, and continuous variables were generally summarised using descriptive statistics $($ mean \pm SD). Statistical analysis was conducted using SPSS V.19.0 (SPSS Inc, Chicago, Illinois, USA). 


\section{RESULTS}

\section{Description of the demographics and MP usage}

Among the 793 children in the two primary schools invited to participate, $781(98.5 \%)$ returned the questionnaires. After $35(4.4 \%)$ incomplete questionnaires were excluded, $746(94.1 \%)$ valid questionnaires were used in the statistical analysis. The participants included 389 (52.1\%) males and $357(47.9 \%)$ females. The average age of the participants in the survey was 10.6 \pm 0.6 years (9-12 years), which was representative of the normal age of the fifth-grade primary school students in China.

A total of $544(72.9 \%)$ participants owned MPs at the time the survey was conducted and the average year of MP usage was $1.3 \pm 1.5$ years. More than half $(53.4 \%)$ of the participants spent fewer than 10 min on calls daily (table 1). The detailed descriptive distributions of sociodemographic characteristics and MP usage are shown in table 1 .

\section{Association between MP use and physical symptoms}

The most frequently reported physical symptom was sleeping problems $(17.8 \%)$, followed by fatigue (13.9\%) and dizziness (12.7\%; figure 1). The result showed that fatigue was significantly associated with both the years of

\begin{tabular}{|c|c|}
\hline Characteristic & Prevalence n (\%) \\
\hline \multicolumn{2}{|l|}{ Sex } \\
\hline Male & $389(52.1)$ \\
\hline Female & $357(47.9)$ \\
\hline \multicolumn{2}{|l|}{ Age, years } \\
\hline 9 & $6(0.8)$ \\
\hline 10 & $341(45.7)$ \\
\hline 11 & $359(48.1)$ \\
\hline 12 & $39(5.2)$ \\
\hline \multicolumn{2}{|l|}{ Rural/urban } \\
\hline Rural & $174(23.3)$ \\
\hline Urban & $572(76.7)$ \\
\hline \multicolumn{2}{|l|}{ MP ownership } \\
\hline Do not own an MP & $202(27.1)$ \\
\hline Own an MP & 544 (72.9) \\
\hline \multicolumn{2}{|l|}{ Years of MP usage } \\
\hline 0 Year & 219 (29.4) \\
\hline 1 Year & 259 (34.7) \\
\hline$>1$ year & 257 (34.5) \\
\hline \multicolumn{2}{|l|}{ Daily duration of calls } \\
\hline $0-10 \mathrm{~min} /$ day & $398(53.4)$ \\
\hline$>10 \mathrm{~min} / \mathrm{day}$ & $132(17.7)$ \\
\hline Characteristic & Mean $\pm S D$ (minimum-maximum) \\
\hline Age & $10.6 \pm 0.6(9-12)$ \\
\hline Height $(\mathrm{cm})$ & $148.5 \pm 6.1(140-190)$ \\
\hline Weight (kg) & $43.0 \pm 11.5(30-75)$ \\
\hline Years of MP usage & $1.3 \pm 1.5(0-8)$ \\
\hline
\end{tabular}

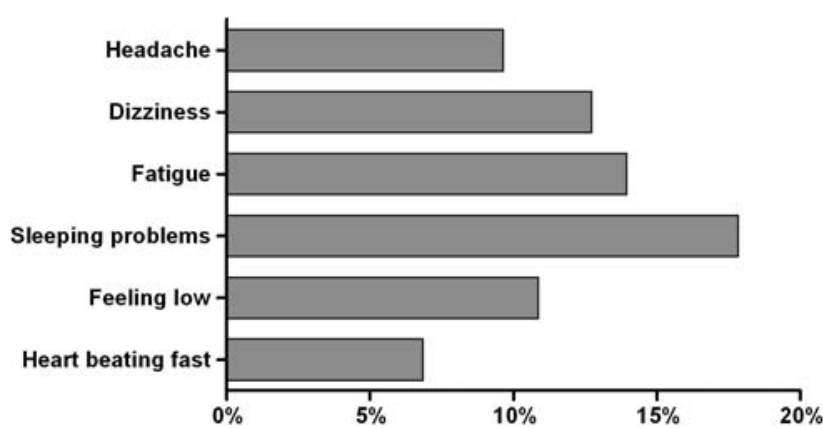

Figure 1 The prevalence of the self-reported physical symptoms $(n=746)$.

MP usage (OR 1.79; 95\% CI 1.07 to 3.00; table 2) and the daily duration of MP calls (OR 2.54; $95 \%$ CI 1.27 to 5.05; table 3). Headache (OR 2.85; 95\% CI 1.23 to 6.57) was significantly associated with the daily duration of MP calls (table 3).

After adjusting for sex, age, rural/urban residence, academic stress, daily exercise and having a recent cold or flu, the association between headache and the daily duration of MP calls was no longer statistically significant. However, the prevalence of fatigue was still significantly associated with the years of MP usage (OR 1.85; 95\% CI 1.07 to 3.22; table 2; see online supplementary 3, Wald value and significance) and the daily duration of MP calls (OR 2.98; 95\% CI 1.46 to 6.12) after adjusting for confounders (table 3; see online supplementary 4, Wald value and significance).

Neither the years of MP usage nor the daily duration of MP calls was found to be significantly associated with other physical symptoms (dizziness, sleeping problems, feeling low or heart beating fast). The $\chi^{2}$ test and logistic regression results for the association between MP usage and selfreported symptoms are presented in tables 2 and 3 .

\section{DISCUSSION}

This is one of the first studies to investigate the potential association between MP use and well-being in children in mainland China. With the growing popularity of MP, children have begun to use MPs at an earlier age and have a longer lifetime exposure to MPs. The MP usage rate in children has reached $72.9 \%$ in our study, and it was higher than the prevalence of MP usage reported in previous similar research in Korea $(64.5 \%),{ }^{2}$ China $(63.2 \%)^{14}$ and Iran $(31.4 \%) .{ }^{15}$ One possible reason was that most of the participants in the present survey lived in an urban area and were more likely to own MPs than a rural population. We investigated the possible association between MP use and well-being in children, and our results revealed that fatigue was significantly associated with MP usage.

Comparing the prevalence of headache, fatigue, sleeping problems and feeling low in this survey with previous studies using the HBSC survey, ${ }^{6}{ }^{16}$ we found an average decrease in participants reporting any present symptoms. 
Table 2 Association between the years of MP usage and well-being in children $(n=746)$

\begin{tabular}{|c|c|c|c|c|c|}
\hline Symptom & Categories of MP usage & $\mathrm{n}(\%)$ & $\mathbf{p}^{\wedge}$ & OR $(95 \% \mathrm{Cl})$ & Adjusted OR (95\% Cl)† \\
\hline \multirow[t]{4}{*}{ Headache } & MP use years & & 0.317 & & \\
\hline & 0 year (ref) & $22(10.0)$ & & 1.00 & 1.00 \\
\hline & 1 year & $20(7.7)$ & & 0.75 (0.40 to 1.41$)$ & 0.60 (0.31 to 1.16$)$ \\
\hline & $>1$ year & $30(11.6)$ & & 1.18 (0.66 to 2.12$)$ & $0.87(0.47$ to 1.62$)$ \\
\hline \multirow[t]{4}{*}{ Dizziness } & MP use years & & 0.778 & & \\
\hline & 0 year (ref) & $31(14.1)$ & & 1.00 & 1.00 \\
\hline & 1 year & $31(11.9)$ & & 0.83 (0.48 to 1.41$)$ & 0.75 (0.42 to 1.32$)$ \\
\hline & $>1$ year & $33(12.8)$ & & $0.89(0.53$ to 1.52$)$ & $0.93(0.57$ to 1.57$)$ \\
\hline \multirow[t]{4}{*}{ Fatigue } & MP use years & & 0.010 & & \\
\hline & 0 year (ref) & $26(11.8)$ & & 1.00 & 1.00 \\
\hline & 1 year & $28(10.8)$ & & 0.90 (0.51 to 1.59$)$ & 0.89 (0.49 to 1.75$)$ \\
\hline & $>1$ year & $50(19.4)$ & & $1.79(1.07 \text { to } 3.00)^{*}$ & $1.85(1.07-3.22)^{\star}$ \\
\hline \multirow[t]{4}{*}{ Sleeping problems } & MP use years & & 0.619 & & \\
\hline & 0 year (ref) & $36(16.4)$ & & 1.00 & 1.00 \\
\hline & 1 year & $46(17.7)$ & & 1.10 (0.68 to 1.77$)$ & $1.05(0.63-1.75)$ \\
\hline & $>1$ year & $51(19.8)$ & & 1.26 (0.79 to 2.02$)$ & $1.25(0.75-2.09)$ \\
\hline \multirow[t]{4}{*}{ Feeling low } & MP use years & & 0.853 & & \\
\hline & 0 year (ref) & $22(10.0)$ & & 1.00 & 1.00 \\
\hline & 1 year & $30(11.9)$ & & 1.17 (0.66 to 2.10$)$ & 1.17 (0.64 to 2.15$)$ \\
\hline & $>1$ year & $29(11.4)$ & & 1.14 (0.63 to 2.05$)$ & 1.28 (0.69 to 2.37 ) \\
\hline \multirow[t]{4}{*}{ Heart beating fast } & MP use years & & 0.182 & & \\
\hline & 0 year (ref) & $13(5.9)$ & & 1.00 & 1.00 \\
\hline & 1 year & $24(9.2)$ & & $1.62(0.80$ to 3.26$)$ & 1.56 (0.75 to 3.24$)$ \\
\hline & $>1$ year & $14(5.4)$ & & 0.91 (0.42 to 1.99$)$ & 0.82 (0.36 to 1.89$)$ \\
\hline
\end{tabular}

One interpretation for the decrease was that younger participants may feel fewer symptoms. The mean age (10.6 years) of participants in our study was younger than that in previous research (12.3 years). ${ }^{16}$ This finding can also be supported by the fact that the prevalence of symptoms in children was lower than that in adolescents. ${ }^{6}$

We observed that children with the highest level of the daily duration of calls felt headache significantly more than did those at other levels. One previous study revealed that participants with a measured exposure to MPs in the highest quartile reported a statistically significantly higher intensity of headache as well. ${ }^{5}$ Sudan $e t a l^{7}$ also found that exposure to MPs was associated with headaches in children. However, the association between headache and MP use was not statistically significant after adjusting for confounding factors. The result was in agreement with those of previous researches that observed a non-significant difference in headaches between MP exposed and non-exposed participants. ${ }^{17-19}$ Since the significant association between headache and MP use occurred only once, we consider that this might be due to chance or multiple testing. ${ }^{6}$

This study indicated the consistently significant associations between fatigue and MP usage, including the years of MP usage and the daily duration of calls. Previous studies have similarly reported that fatigue was associated with MP usage. ${ }^{2} 21$ Moreover, all of the associations reached statistical significance at the highest level of MP usage. Ikeda $e t$ al also found that fatigue in those with longer MP use ( $>33 \mathrm{~h} /$ week) of MP use was significantly higher than others. A possible reason was that the fatigue related to MP use was more likely to be a mental disorder than a physiological one, due to longtime MP exposure serving as a chronic stressor. ${ }^{20}$ Sleep disturbance was reported as a significant contributor to fatigue. ${ }^{22}$ Sleep quality worsened ${ }^{23}{ }^{24}$ or sleep duration shortened $^{23}{ }^{25-27}$ with increasing MP use time. Maybe that is another reason for the association between fatigue and MP usage. On the other hand, no significant $^{10}$ or an inverse association ${ }^{28}$ between MP use and fatigue has been reported. These studies were based on adults or teenagers, whereas we focused on children. Children may be more sensitive and vulnerable to electromagnetic fields produced by MPs than adults, and this difference may explain the controversial results. ${ }^{3} 429$

The prevalence of dizziness, sleeping problems, feeling low and heart beating fast were not significantly affected by the different classifications of MP usage in our study. The result was in line with some previous similar researches that have indicated no significant association between dizziness, ${ }^{5} 63031$ sleeping problems, ${ }^{32}$ feeling low ${ }^{16} 33$ and MP use. Nonetheless, some crosssectional studies have revealed that MP users have complained of dizziness, ${ }^{2} 34$ sleeping problems ${ }^{23}{ }^{24}$ and 
Table 3 Association between the daily duration of MP calls and well-being in children $(n=746)$

\begin{tabular}{|c|c|c|c|c|c|}
\hline Symptom & Categories of MP usage & n (\%) & $\mathbf{p}^{\wedge}$ & OR $(95 \% \mathrm{Cl})$ & Adjusted OR (95\% Cl)† \\
\hline \multirow[t]{5}{*}{ Headache } & $\begin{array}{l}\text { Duration of calls } \\
1 \text { year }\end{array}$ & & 0.079 & & \\
\hline & $0-10 \mathrm{~min} /$ day (ref) & $13(6.6)$ & & 1.00 & 1.00 \\
\hline & $\begin{array}{l}>10 \mathrm{~min} / \text { day } \\
>1 \text { year }\end{array}$ & $7(13.0)$ & & 2.12 (0.80 to 5.61$)$ & 1.71 (0.60 to 4.92$)$ \\
\hline & $0-10 \mathrm{~min} / \mathrm{day}$ & $18(9.7)$ & & $1.53(0.73$ to 3.23$)$ & $1.28(0.60$ to 2.75$)$ \\
\hline & $>10 \mathrm{~min} /$ day & $12(16.7)$ & & $2.85(1.23 \text { to } 6.57)^{\star}$ & 2.35 (0.97 to 5.70$)$ \\
\hline \multirow[t]{5}{*}{ Dizziness } & $\begin{array}{l}\text { Duration of calls } \\
1 \text { year }\end{array}$ & & 0.471 & & \\
\hline & $0-10 \mathrm{~min} /$ day (ref) & $21(10.6)$ & & 1.00 & 1.00 \\
\hline & $\begin{array}{l}>10 \mathrm{~min} / \text { day } \\
>1 \text { year }\end{array}$ & $10(18.5)$ & & 1.92 (0.84 to 4.36$)$ & 1.48 (0.61 to 3.62$)$ \\
\hline & $0-10 \mathrm{~min} / \mathrm{day}$ & $23(12.4)$ & & 1.26 (0.67 to 2.34$)$ & 1.22 (0.59 to 2.17$)$ \\
\hline & $>10 \mathrm{~min} /$ day & 10 (13.9) & & $1.36(0.61$ to 3.05$)$ & $1.28(0.56$ to 2.97$)$ \\
\hline \multirow[t]{5}{*}{ Fatigue } & $\begin{array}{l}\text { Duration of calls } \\
1 \text { year }\end{array}$ & & 0.025 & & \\
\hline & 0-10 min/day (ref) & $23(11.6)$ & & 1.00 & 1.00 \\
\hline & $\begin{array}{l}>10 \mathrm{~min} / \text { day } \\
>1 \text { year }\end{array}$ & $5(9.3)$ & & 0.78 (0.28 to 2.15$)$ & 0.80 (0.28 to 2.27$)$ \\
\hline & 0-10 min/day & $32(17.2)$ & & 1.59 (0.89 to 2.84$)$ & 1.63 (0.89 to 2.99$)$ \\
\hline & $>10 \mathrm{~min} /$ day & $18(25.0)$ & & $2.54(1.27 \text { to } 5.05)^{\star}$ & $2.98(1.46 \text { to } 6.12)^{\star}$ \\
\hline \multirow[t]{5}{*}{ Sleeping problems } & $\begin{array}{l}\text { Duration of calls } \\
1 \text { year }\end{array}$ & & 0.204 & & \\
\hline & $0-10 \mathrm{~min} /$ day (ref) & 32 (16.2) & & 1.00 & 1.00 \\
\hline & $\begin{array}{l}>10 \mathrm{~min} / \text { day } \\
>1 \text { year }\end{array}$ & $14(25.9)$ & & 1.82 (0.89 to 3.72$)$ & 1.51 (0.69 to 3.28$)$ \\
\hline & $0-10 \mathrm{~min} /$ day & $33(17.7)$ & & $1.13(0.66$ to 1.92$)$ & 1.12 (0.63 to 1.98$)$ \\
\hline & $>10 \mathrm{~min} /$ day & $18(25.0)$ & & 1.73 (0.90 to 3.33$)$ & $1.82(0.89$ to 3.70$)$ \\
\hline \multirow[t]{5}{*}{ Feeling low } & $\begin{array}{l}\text { Duration of calls } \\
1 \text { year }\end{array}$ & & 0.576 & & \\
\hline & $0-10 \mathrm{~min} /$ day (ref) & $20(10.1)$ & & 1.00 & 1.00 \\
\hline & $\begin{array}{l}>10 \mathrm{~min} / \text { day } \\
>1 \text { year }\end{array}$ & $9(16.7)$ & & 1.78 (0.76 to 4.17$)$ & 1.56 (0.64 to 3.85$)$ \\
\hline & $0-10 \mathrm{~min} /$ day & $20(10.8)$ & & 1.08 (0.56 to 2.08$)$ & 1.14 (0.58 to 2.34$)$ \\
\hline & $>10 \mathrm{~min} /$ day & 9 (12.5) & & $1.27(0.55$ to 2.94$)$ & $1.44(0.61$ to 3.38$)$ \\
\hline \multirow[t]{5}{*}{ Heart beating fast } & $\begin{array}{l}\text { Duration of calls } \\
1 \text { year }\end{array}$ & & 0.375 & & \\
\hline & $0-10 \mathrm{~min} /$ day (ref) & $19(9.6)$ & & 1.00 & 1.00 \\
\hline & $\begin{array}{l}>10 \mathrm{~min} / \text { day } \\
>1 \text { year }\end{array}$ & $5(9.3)$ & & 0.96 (0.34 to 2.71$)$ & 0.62 (0.19 to 1.99$)$ \\
\hline & $0-10 \mathrm{~min} /$ day & $10(5.4)$ & & $0.54(0.24$ to 1.19$)$ & $0.47(0.21$ to 1.06$)$ \\
\hline & $>10 \mathrm{~min} /$ day & $4(5.6)$ & & $0.55(0.18$ to 1.69$)$ & $0.36(0.10$ to 1.29$)$ \\
\hline
\end{tabular}

depressed $\operatorname{mood}^{21}$ more frequently according to the time of MP usage. These controversial conclusions might be due to the different valuation methods used to determine MP exposure. More than half of the above researches that did not find significant associations between MP use and well-being were assessed by dosimetry $^{5}{ }^{32}$ or MP exposure experimental studies. ${ }^{18}{ }^{33}$ As self-reported exposure did not count as real MP exposure, the observed associations were mostly likely due to differential misclassification based on an overestimation of self-reported exposure and subjective symptoms. ${ }^{5}$
This cross-sectional survey is one of the first studies that investigated the association between MP use and well-being in Chinese children. The schools that we chose were typical and participants in our research are representative of primary school students in China. The response rate $(98.5 \%)$ in this study was higher than that in previous similar cross-sectional studies in Japan $(84.4 \%),{ }^{23}$ Turkey $(90.8 \%)^{35}$ and Sweden $(63.5 \%){ }^{36}$ One possible explanation was that the questionnaire survey was administered during class. In our study, academic stress, daily exercise and having a recent cold or 
flu were taken into account as confounding factors, as well as sex, age, rural/urban residence, to improve the reliability of the results.

A limitation of this research was that the crosssectional study design could not adequately reveal the causality of the factors. ${ }^{37}$ To reduce the misclassification of self-reported MP usage, we would obtain detailed phone call data from a mobile service supplier or use personal dosimeters to assess individual exposure to MPs. The unavailable validity data for the Chinese version of the HBSC questionnaire were another limitation of this study. Since only a small number of symptoms were examined in this study, we do not consider our study to be conclusive. More comprehensive research is needed to explore the associations between MP usage and well-being in children.

\section{CONCLUSIONS}

In general, this study indicates a significant association between fatigue in children and their MP use including the years of MP usage and the daily duration of calls. Since the significant association between headache and MP use was a single occurrence, we consider that this might be due to chance or multiple testing. Further in-depth research is needed to explore the potential health effects of MP use in children.

Acknowledgements The authors would like to thank Dr Xiangyu Ma (Department of Epidemiology, Third Military Medical University) for discussion on questionnaire design and Dr Xiaolu Zeng (Department of Epidemiology, Third Military Medical University), Dr Dihui Ma (Department of Health Statistics, Third Military Medical University) for consultation on statistical analysis. The authors would also like to thank Yonghui Lu, Tao Zhang, Ling Mao and Gang Zhu for helping with the distribution and collection of questionnaires, and all of the participants and teachers for their participation.

Contributors FZ, ZY and LZ were involved in the study concept and design, as well as in the critical revision of the manuscript for important intellectual content and study supervision. FZ, PG, MH, ML, JT, DC, ZZ, ZY and LZ were involved in the acquisition of data. FZ and PG were involved in the data analysis and interpretation. LZ and FZ were involved in the drafting of the manuscript. All authors were involved in approving the final version for publication.

Funding This work was supported by the National Basic Research Programme of China (National 973 Programme: grant no. 2011CB503700) and National Natural Science Foundation of China (grant nos. 31370833 to LZ).

Competing interests None declared.

Patient consent Obtained

Ethics approval The protocol of this study was approved by the Third Military Medical University Ethical Committee (see online supplement 5). All study participants obtained written consent from their parents or guardians.

Provenance and peer review Not commissioned; externally peer reviewed.

Data sharing statement No additional data are available.

Open Access This is an Open Access article distributed in accordance with the Creative Commons Attribution Non Commercial (CC BY-NC 4.0) license, which permits others to distribute, remix, adapt, build upon this work noncommercially, and license their derivative works on different terms, provided the original work is properly cited and the use is non-commercial. See: http:// creativecommons.org/licenses/by-nc/4.0/

\section{REFERENCES}

1. Bercedo Sanz A, Redondo Figuero C, Pelayo Alonso R, et al. Mass media consumption in adolescence. An Pediatr (Barc) 2005;63:516-25.

2. Byun $\mathrm{YH}, \mathrm{Ha} \mathrm{M}, \mathrm{Kwon} \mathrm{HJ}$, et al. Epidemiological characteristics of mobile phone ownership and use in Korean children and adolescents. Environ Health Toxicol 2013;28:e2013018.

3. Söderqvist F, Carlberg M, Hansson Mild K, et al. Childhood brain tumour risk and its association with wireless phones: a commentary. Environ Health. 2011;10:106.

4. Independent Expert Group on Mobile Phones (IEGMP). Mobile Phones and Health (Stewart Report). 2010. http://webarchive. nationalarchives.gov.uk/20101011032547/http://www.iegmp.org.uk/ report/clarification.htm (accessed 12 Oct 2014).

5. Heinrich S, Thomas S, Heumann C, et al. Association between exposure to radiofrequency electromagnetic fields assessed by dosimetry and acute symptoms in children and adolescents: a population based cross-sectional study. Environ Health 2010;9:75.

6. Heinrich S, Thomas S, Heumann C, et al. The impact of exposure to radio frequency electromagnetic fields on chronic well-being in young people-a cross-sectional study based on personal dosimetry. Environ Int 2011;37:26-30.

7. Sudan M, Kheifets L, Arah O, et al. Prenatal and postnatal cell phone exposures and headaches in children. Open Pediatr Med J 2012;6:46-52.

8. Zheng $\mathrm{F}$, Gao $\mathrm{P}, \mathrm{He} \mathrm{M}$, et al. Association between mobile phone use and inattention in 7102 Chinese adolescents: a population-based cross-sectional study. BMC Public Health 2014;14:1022.

9. Thomas S, Heinrich S, von Kries R, et al. Exposure to radio-frequency electromagnetic fields and behavioural problems in Bavarian children and adolescents. Eur J Epidemiol 2010;25:135-41.

10. Choi SB, Kwon MK, Chung JW, et al. Effects of short-term radiation emitted by WCDMA mobile phones on teenagers and adults. BMC Public Health 2014;14:438.

11. Loughran SP, Benz DC, Schmid MR, et al. No increased sensitivity in brain activity of adolescents exposed to mobile phone-like emissions. Clin Neurophysiol 2013;124:1303-8.

12. Trunk A, Stefanics $G$, Zentai N, et al. No effects of a single 3G UMTS mobile phone exposure on spontaneous EEG activity, ERP correlates, and automatic deviance detection. Bioelectromagnetics 2013;34:31-42

13. Haugland S, Wold B, Stevenson J, et al. Subjective health complaints in adolescence: a cross-national comparison of prevalence and dimensionality. Eur J Publ Health 2001;11:4-10.

14. Chiu CT, Chang YH, Chen CC, et al. Mobile phone use and health symptoms in children. J Formos Med Assoc 2014. Published Online First 9 Aug 2014. doi:10.1016/j.jfma.2014.07.002

15. Mortazavi SM, Atefi M, Kholghi F. The pattern of mobile phone use and prevalence of self-reported symptoms in elementary and junior high school students in Shiraz, Iran. Iran J Med Sci 2011;36:96-103.

16. Redmayne M, Smith E, Abramson MJ. The relationship between adolescents' well-being and their wireless phone use: a crosssectional study. Environ Health 2013;12:90.

17. Oftedal G, Straume A, Johnsson A, et al. Mobile phone headache: a double blind, sham-controlled provocation study. Cephalalgia 2007;27:447-55.

18. Cinel C, Russo R, Boldini A, et al. Exposure to mobile phone electromagnetic fields and subjective symptoms: a double-blind study. Psychosom Med 2008;70:345-8.

19. Berg-Beckhoff G, Blettner M, Kowall B, et al. Mobile phone base stations and adverse health effects: phase 2 of a cross-sectional study with measured radio frequency electromagnetic fields. Occup Environ Med 2009;66:124-30.

20. Ikeda K, Nakamura K. Association between mobile phone use and depressed mood in Japanese adolescents: a cross-sectional study. Environ Health Prev Med 2014;19:187-93.

21. Szyjkowska A, Gadzicka E, Szymczak W, et al. The risk of subjective symptoms in mobile phone users in Poland-an epidemiological study. Int J Occup Med Environ Health 2014;27:293-303.

22. Strober LB. Fatigue in multiple sclerosis: a look at the role of poor sleep. Front Neurol 2015;6:21.

23. Munezawa T, Kaneita $Y$, Osaki $Y$, et al. The association between use of mobile phones after lights out and sleep disturbances among Japanese adolescents: a nationwide cross-sectional survey. Sleep 2011;34:1013-20.

24. Sahin S, Ozdemir K, Unsal A, et al. Evaluation of mobile phone addiction level and sleep quality in university students. Pak J Med Sci 2013;29:913-18. 
25. Jiang X, Hardy LL, Baur LA, et al. Sleep duration, schedule and quality among urban Chinese children and adolescents: associations with routine after-school activities. PLOS ONE 2015;10:e0115326.

26. Arora T, Hussain S, Hubert Lam KB, et al. Exploring the complex pathways among specific types of technology, self-reported sleep duration and body mass index in UK adolescents. Int $J$ Obes (Lond) 2013;37:1254-60.

27. Yang YS, Yen JY, $\mathrm{Ko} \mathrm{CH}$, et al. The association between problematic cellular phone use and risky behaviors and low self-esteem among Taiwanese adolescents. BMC Public Health 2010;10:217.

28. Thomas $\mathrm{S}$, Kühnlein $\mathrm{A}$, Heinrich $\mathrm{S}$, et al. Personal exposure to mobile phone frequencies and well-being in adults: a cross-sectional study based on dosimetry. Bioelectromagnetics 2008;29:463-70.

29. Kheifets L, Repacholi M, Saunders R, et al. The sensitivity of children to electromagnetic fields. Pediatrics 2005;116:e303-13.

30. Balikci K, Cem Ozcan I, Turgut-Balik D, et al. A survey study on some neurological symptoms and sensations experienced by long term users of mobile phones. Pathol Biol 2005;53:30-4.

31. Mortazavi SM, Ahmadi J, Shariati M. Prevalence of subjective poor health symptoms associated with exposure to electromagnetic fields among university students. Bioelectromagnetics 2007;28:326-30.
32. Mohler E, Frei P, Fröhlich J, et al. Exposure to radiofrequency electromagnetic fields and sleep quality: a prospective cohort study. PLOS ONE 2012;7:e37455.

33. Hillert L, Akerstedt T, Lowden A, et al. The Effects of $884 \mathrm{MHz}$ GSM wireless communication signals on headache and other symptoms: an experimental provocation study. Bioelectromagnetics 2008;29:185-96.

34. Küçer N, Pamukçu T. Self-reported symptoms associated with exposure to electromagnetic fields: a questionnaire study. Electromagn Biol Med 2014;33:15-17.

35. Hassoy H, Durusoy R, Karababa AO. Adolescents' risk perceptions on mobile phones and their base stations, their trust to authorities and incivility in using mobile phones: a cross-sectional survey on 2240 high school students in Izmir, Turkey. Environ Health 2013;12:10.

36. Söderqvist F, Carlberg M, Hardell L. Use of wireless telephones and self-reported health symptoms: a population-based study among Swedish adolescents aged 15-19 years. Environ Health 2008;7:18.

37. Zhi S, Guoying D, Jipeng L, et al. Correlational analysis of neck/ shoulder pain and low back pain with the use of digital products, physical activity and psychological status among adolescents in Shanghai. PLOS ONE 2013;8:e78109. 